\title{
School Variables and Inclination towards Dropout of Secondary School Students: A Case Study
}

\author{
Abisola Oladeni Sakirudeen ${ }^{a}$, \& Taiwo Akinloye ${ }^{\text {b }}$
}

Received: 21 June 2020 Accepted: 17 September 2020

\begin{abstract}
This study was carried out to investigate school variables and inclination towards the dropout of secondary school students in Akwa Ibom State (Nigeria). Four research questions and four null hypotheses were formulated to guide the study. An expost facto research design was adopted for the study. The population of 16,639 Senior Secondary School two (SS2) students with a sample of 300 students selected from 6 public secondary schools in the study area. For the study, the "School Variables and Inclination towards Dropout questionnaire (SVIDQ)" were used to obtain data from the respondents. The research instrument has a 4 - point rating scale. Cronbach Alpha reliability method was used in establishing the reliability of the instrument and a reliability coefficient of .84 was realized. After the administration, scoring, and collation of the instrument, the data obtained were subjected to the dependent t-test analysis. All the null hypotheses were tested at a 0.05 level of significance. All were rejected showing that test/examination, co-curricular activities, school rules and regulations, and teacher-student relationship significantly influence inclination towards dropout of secondary school students. It is recommended that the government should employ more teachers to help curb the discrepancies of the teacher-student ratio to enhance a positive teacher-student relationship. This would be more important for greater educational success and improved promotion to university.
\end{abstract}

Key Words: school dropout; teacher-student relationship; educational promotion; educational success; curricular activities; educational variables.

\footnotetext{
${ }^{\mathrm{a}}$ University of Uyo (Nigeria) (DORCID 0000-0002-4931-9077 ${ }^{\mathrm{b}}$ Assanusiyyah College of Education (Nigeria). Correspondence: Abisola Oladeni Sakirudeen. Department of Educational Foundations, Guidance and Counselling. Faculty of Education. University of Uyo, Uyo Akwa Ibom State, Nigeria. abisola4u@gmail.com
} 


\section{Introduction}

The schools handled in Nigeria by colonial administration after independence in 1960 were retrogressive defective and perhaps attempts making the nation schools growth backward. The system failed to meet the needs and aspirations of the nation in terms of her manpower to savage the requirements for national development. Every society has some kind of arrangement for bringing up and training her young ones to prepare them for life. The Nigeria philosophy of education is based on the development of the individual into a sound and effective citizen and the provision of equal educational opportunities for all citizens of the country at the primary, secondary and tertiary levels, both inside and outside the formal school system. Thus, education is a basic requisite for the development of responsible citizenship, maintenance of productive ways of life, and successful preparation for entry into the dynamic working world.

Secondary education is the form of education children receive after primary education and before tertiary education. In this respect, secondary school education is viewed as very crucial since it is at this level of education that students are prepared for entering into tertiary level education. It is also at this stage that a child's fate in respect of what he will become in the future, particularly about career direction is decided. The importance of secondary education as preparation for useful living within the society and preparation for higher education cannot be overemphasized (Federal Republic of Nigeria, 2013). However, many students dropout of secondary schools and unable to acquire secondary education despite its importance. There are many reasons for students' dropout of which may include curricular activities, school problems, school rules and regulations, family problems, and teachers' relationship with students. Other factors include poor lack of recreational facilities, the geographical location of the school, financial constraints, and other personal-social problems. According to William (1971), when a student drops out of school, his behavior generates a variety of reactions from the social milieu, school, parents, peers, and even from his or her self.

The inclination to dropout of schools has not only assumed disturbing proportion, they have also become one of the current problems facing educational development in the country generally. The government has stepped in by issuing directives threatening parents who withdraw their wards prematurely from the school system with a prosecution. A good example is the Universal Basic Education Law passed by the Akwa Ibom State House of Assembly on June 23, 2005 (Udo, 2005). There is also the recent declaration of free and compulsory education for all children in primary and secondary school levels in Akwa Ibom state. The failure to complete school has severe consequences for the individual as well as for the society. 
Inclination means a natural tendency or urges to act or feel in a particular way. It is an individual's disposition towards a particular action or event. The inclination to dropout refers to the tendency or urges of a student to discontinue school with or without reasons. It is the fondness of students' attitude towards giving-up on their schooling. Rosenberg (1960) defines inclination as a way a person feels, acts, or responds in a particular way towards specific events or objects. According to him, when the inclination is studied, what will be observed are the evoking stimuli on one hand and the various types of responses on the other. Viewed against this description, an inclination must therefore have a behavioral component because a response predisposition must lead to some actions like dropping out of school when it is suitably activated.

The idea of dropping out describes the process by which a person discontinues or refrains from continuing with what he sets out to do. Applying it to the school situation, it refers to the process of withdrawing from or discontinuing formal school attendance before graduation without reason. According to Austin (2006: 22), "a student who leaves school for any reason except death, suspension, or expulsion before graduation or completion of a program of study and without transferring to another school can be classified as dropout". Based on this understanding, the term 'dropout' is used to describe a student who could not complete his/her education at any level due to one reason or the other (Austin, 2006). Austin also views the term in educational spheres as the act of withdrawing from school officially or unofficially. Students' tendency to dropout of school cannot be studied in isolation.

School variables are those factors from the school environment that could cause students to drop out from school before graduation such variables include facilities, social groups, school infrastructure, teachers-students relationship, and school activities (Donnelly, 2015). For instance, Donnelly (2015) maintained that the way a student views his/her school environment determines the extent of commitment to school activities till graduation.

As stated by Hembree (2008) students who perceive that they cannot withstand the learned helplessness experienced in testing situations, anticipated punishment for failure, and lack self-efficacy in testing situations may decide to drop out of school to avoid harassment and embarrassment. Participation in tests and examinations causes anxiety in students that forces them to divide their attention between behaviors relevant to the task of somatic concerns and other anti-social behaviors (Hambree, 2008). Additionally, students with high levels of anxiety as a result of participation in tests and examinations tend to study more, yet they retain their belief that they will still perform poorly on the assessment and they display difficulty in encoding the information that they have studied exhaustively (Ormord, 2011). If this situation finally occurs in the tests and examinations, the students try to 
avoid subsequent tests and examinations, exhibit dropout tendencies, and finally dropout (Ormrod, 2011).

According to Milderd (1954), Crowder (2003), Narayanan and Murphy (2017), most students engage in partying which makes them also involve in smoking and clubbing. They stated further that partying requires money and distracts students from school; students dropout of school to engage in some forms of economic activities that can fetch them money for their social activities. Most parties take place at the night. Students who involve in night parties go to bed late and find it difficult to wake up early enough and prepare for school, thereby making them stay away from school. This continuous activity can make them incline towards dropping out of school. These authors noted that most students, who party a lot avoid school, engage in cultism, stealing, and armed robbery.

Sound rules and regulations of a school checkmate students' substance abuse and other delinquent behavior, except for the bad students who still indulge in negative behaviors and when they are severely punished for their acts, they may decide to leave the school (Johnson, 2013). More specifically, sound rules and regulations are linked to lower levels of drug use as well as less report of delinquent attitudes among students (Loukas, 2006). Students perceive school climate, appropriate rules, and regulations as predictive of better psychological well-being, good academic achievement, and mitigate against dropping out of school in their early secondary school education (Anderson, 1982). Studies have shown that school rules and regulations correlate highly with decreased student absenteeism and dropping out of school (Dejung and Kenneth, 1986), and with a lower rate of student suspension (Gregory and Fan, 2011).

Interpersonal relationships between teachers and students may contribute to students' wanting to drop out of school. For example, if a teacher has lower expectations for, or responds negatively to certain students, achievement by such students may be negatively affected and the students might drop out of school. In some schools, there is often less emotional support from teachers, more emphasis is on their relative ability and competition to their examination or test. There is a bridge decreased in social contact between teachers and students which can hinder them in achieving their educational goals and this could lead them from wanting to leave school without completion of their studies (Bridgeland, Diblulio and Balfanz 2009). Students must be able to identify with their teachers and connect to the school environment for effective learning and school completion.

In essence, school variables and inclination towards dropout of secondary school students in Akwa Ibom State are focused on the impression develop about what school stands for based on their personal and environmental or social background. The study also investigates how these 
school variables impact on students' sense of judgment which predicts their continued adjustment to schooling or possible dropout from school.

\section{Background}

The continued high rate of dropouts among secondary school students in Akwa Ibom State demands critical study considering its negative consequences on the social-economic lives of the individuals and society. Personal observations by the researcher reveal that many criminal activities appear to be perpetrated in the study area by youths who dropped out of school. This development has become a cause of serious concern to all wellmeaning Akwa Ibomites. This development suggests that the educational system in the area of study needs very serious attention to attain expected goals. The consequences of dropout to both students and society are substantial and far-reaching.

The researcher personally observes that most of these students after the completion of their senior secondary find it difficult to continue to a higher educational level. A good number of students just stay away from school on several occasions without reasonable excuses. If this situation continues, the economy and means of livelihood as well as the development of the state may be threatened. The money spent by the State Government to provide free and compulsory education for them would have been wasted.

The inclination to dropout is unfortunate for students, particularly in this age of technological development where idle hands are easily exposed to crimes and their consequences. Most secondary school students see curricular activities in schools such as examination as being too difficult and timeconsuming. Some view school as a cage where people are given rules and regulations to abide with. A greater number of students see schooling as too demanding where teachers and students are rivals with each other. While a majority of the students in secondary school view co-curricular activities as laborious.

Considering the high level of drop-out in the study area and the need to is that those school variables which could influence students' tendency to drop out of school, the researcher, therefore, carried out this study and focused on school variables such as school challenges, writing an examination, co-curricular activities, and school rules and their influences on students' inclination to dropout in Akwa Ibom State.

\section{Objectives}

The purpose of the study was to investigate school variables and inclination towards dropout of secondary school students in Akwa Ibom State. Specifically, the study sought to: 
i. Determine the influence of students' attitude to examination on the inclination towards dropout

ii. Determine the influence of Co-curricular activities on the inclination towards dropout

iii. Determine the influence of school rules and regulations on the inclination towards dropout

iv. Determine the influence of teacher-student relationship on the inclination towards dropout

\subsection{Significance of the study}

The findings of this study would be a benefit to teachers, school principals, school counselors, students, parents, government, and future researchers. The findings of this study would guide secondary school teachers on how to make curricular activities to be pleasurable to counter dropout tendencies among secondary school students. The findings on the teacherstudent relationship would give teachers insight on how to encourage students with tendencies to drop out of school and deal with such tendencies. This would necessarily precipitate changes in the style of school governance and student-teach interactions and relations.

Through the findings of this study, it would enable principals to use necessary strategies to ensure that rules and regulations are jointly fixed by school authority and students. The findings of the study on family support would give the school counselors enough information and insight into the workings of family influences, and interpersonal relationship between parents and students and how these can influence adolescent decision-making. This is so because most of the decisions to join cult groups or be involved in other anti-social activities which may lead to dropout may emanate from informal systems of friendship.

Concerning students would understand the negative consequences of dropping out of school and persevere till they finish their school for a better future. Students would also use the findings and recommendations of this study as guideposts towards eliminating perception about schooling and see schooling as a worthwhile event.

In terms of family, support would enable parents to develop strategies to use in motivating their children to continue in school through adequate provision of supports. It is hoped that the findings of this study would bridge the gap between the school and home as it may lead to teachers and counselors redefining their roles and broadening the perspectives of their jobs and roles to extend beyond school boundaries into the home at-risk students. The point here is to help draw parents into the process of schooling and education of their children.

The findings of this study would give education policy makers adequate information to guide them in their educational policy implementation, 
especially regarding free and compulsory education. The findings would be of immense benefit to future researchers as the findings would boost their empirical studies.

\subsection{Research Questions}

The following research questions were formulated to guide the study.

1. How do students attitude to examination influence inclination towards dropout

2. How do co-curricular activities influence inclination towards dropout

3. How do school rules and regulations influence inclination towards dropout

4. In what way does the teacher-student relationship influence inclination towards dropout.

\subsection{Research Null Hypotheses}

i. There is no significant influence of students attitude to examination on the inclination towards dropout

ii. There is no significant influence of co-curricular activities on the inclination towards dropout

iii. There is no significant influence of school rules and regulations on the inclination towards dropout

iv. There is no significant influence of the teacher-student relationship on the inclination towards dropout.

\section{Methods}

\subsection{Methodology}

The researcher adopted an ex-post facto research design. This was deemed appropriate because the researcher did not have direct control of the independent and dependent variables since their manifestations have already occurred and cannot be manipulated. Isaac and Michael (2005) noted that the ex-post facto research design method is often used instead of the experimental design method to test hypotheses about causes and effect relationships among variables that cannot be manipulated experimentally. The sample size of this study consisted of 300 senior school Two (SS2) students from 6 public secondary schools. In each sampled school, 50 students were selected to take part as the respondents.

\subsection{Instrumentation}

The researcher developed an instrument for data collection called "School Variables and Inclination towards Dropout Questionnaire (SVITDQ)". Experts in Test and Evaluation in the Department of Educational 
Foundation, Guidance, and Counseling, Faculty of Education, University of Uyo, critically scrutinized the contents of the questionnaire. The validators affected necessary corrections on the draft copy before accepting it suitable for further procedures. The questionnaire comprised of two sections, A and B. Section A comprised of items on the independent variables, section B comprised of items on Inclination toward dropping out. The instrument had a 4-point rating scale as follows: Strongly Agree (SA), Agree (A), Disagree (D), Strongly Disagree (SD).

\section{Results}

\subsection{Research Question One}

How do students' attitudes to examination influence the inclination towards dropout of secondary school students in Akwa Ibom State?

\begin{tabular}{lllll}
\hline Attitude to Test/Examination & n & Mean & SD & Mean Diff \\
\hline High & 167 & 30.58 & 8.04 & \\
Low & 133 & 24.46 & 9.12 & \\
\hline Field Work, 2020 & & & &
\end{tabular}

Table 1. Mean and Standard Deviation Scores on Influence of Students Attitude to Test/Examination and Inclination towards Dropout

As shown in Table 1 on the influence of students' attitude to test/examination and inclination towards dropout shows a mean of 30.58 and 24.46 respectively with a mean difference of 8.22. students whose mean scores on attitude towards tests/examination were above the median score of 14.01 were 167 , while those whose mean scores were lesser than the median score of 133. The result shows that students' attitude towards tests/examination has a high influence on their tendency to dropout of school. This result implies that students who view tests/examinations positively are more likely to continue in school than those who perceive it negatively.

\subsection{Research Question Two}

How do co-curricular activities influence the inclination towards dropout of secondary school students in Akwa Ibom State?

\begin{tabular}{lcccc}
\hline Co-Curricular Activities & n & Mean & SD & Mean Diff \\
\hline High & 171 & 25.89 & 4.76 & \\
Low & 129 & 19.61 & 6.32 & 5.21 \\
\hline Field Work, 2020 & & & &
\end{tabular}

Table 2. Mean and Standard Deviation Scores on Influence of Students Attitude to CoCurricular Activities and Inclination towards Dropout 
As shown in Table 2, the calculated mean scores of 25.89 and 19.61 for high and low influence of Co-curricular activities on students' inclination towards dropout respectively based on the median score of 6.0. A mean difference of 5.21 was also realized. From the result, it was found that the mean score in inclination towards dropout for high influence is greater than that of the low influence hence, it shows that co-curricular activities have an influence on students' inclination to dropout.

\subsection{Research Question Three}

How do school rules and regulations influence the inclination towards dropout of secondary school students in Akwa Ibom State?

\begin{tabular}{lllll}
\hline School Rules and Regulations & n & Mean & SD & Mean Diff \\
\hline High & 183 & 32.11 & 7.48 & \\
Low & 117 & 21.01 & 6.89 & 8.04 \\
\hline Field Work, 2020 & & & &
\end{tabular}

Table 3. Mean and Standard Deviation Scores on Influence of Students Attitude to School Rules and Regulations and Inclination towards Dropout

The result as presented in Table 3 indicates mean scores of 32.11 and 21.01 for the high and low influence of school rules and regulation on students' inclination to dropout respectively with a mean difference of 8.04. students with mean scores above the median score of 6.0 were 32.11 , while those scores lesser than the median score (6.0) were 117. The result shows that school rules and regulations have a high influence on students' inclination towards dropout. This implies that students who perceive school rules and regulations positively are less likely to dropout of school than their counterparts who perceive it negatively.

\subsection{Research Question Four}

In what way does the teacher-student relationship influence inclination towards the dropout of secondary school students in Akwa Ibom State?

\begin{tabular}{lllll}
\hline Teacher-Student Relationship & n & Mean & SD & Mean Diff \\
\hline High & 163 & 39.43 & 5.78 & 9.01 \\
Low & 137 & 30.17 & 6.00 & \\
\hline
\end{tabular}

Field Work, 2020

Table 4. Mean and Standard Deviation Scores on Influence of Students Teacher-Student Relationship and Inclination towards Dropout 
Table 4 shows mean scores of 39.43 for those above the median score and 30.17 for those less than the median score and a mean difference of 9.01 for teacher-student relationship and students' dropout tendency. Students with high influence of teacher-student relationship were more than those with low high influence. The result indicates that the teacher-student relationship has a high influence on their inclination to dropout of school. The result implies that students who view teacher-student relationships positively are less likely to dropout of school than those who perceived it negatively.

\section{6. $\mathrm{Hol}$}

There is no significant influence of students' attitude to test/examination on the inclination towards dropout of secondary school students in Akwa Ibom State?

\begin{tabular}{lllllll}
\hline Variables & n & Mean & SD & df & t.vahe $_{\text {- }}$ & t.Cal \\
\hline Test/Examinations & 300 & 13.66 & 5.25 & \multirow{2}{*}{299} & 1.96 & -13.49 \\
Dropout Tendency & 300 & 19.56 & 7.02 & & & \\
\hline
\end{tabular}

Field Work, 2020 Significant at $P<0.05$ alpha level, $t$-cal $=-13.49, t$-crit $=1.96, d f=299$

Table 5. Summary of Dependent t-test Analysis of Influence of Test/Examinations on Inclination towards Dropout of Secondary School Students

The analysis in Table 5 produced a calculated value of -13.49 when compared to the critical t-value of 1.96 at a .05 level of significance with 299 degrees of freedom, it was found that the t-value is greater than the calculated value. Based on this finding, the null hypothesis which stated that there is no significant influence of students' attitude to test/examinations on the inclination towards dropout was not retained. This implies that there was a significant influence of test/examinations on the inclination towards the dropout of secondary school students.

\section{7. $\mathrm{Ho} 2$}

There is no significant influence of co-curricular activities on the inclination towards dropout of secondary school students in Akwa Ibom State?

\begin{tabular}{lllllll}
\hline Variables & n & Mean & SD & df & t-vahe $_{\text {-val }}$ & t.Cal \\
\hline Co-curricular Activities & 300 & 10.08 & 5.01 & \multirow{2}{*}{299} & 1.96 & -9.69 \\
Dropout Tendency & 300 & 20.46 & 9.78 & & & \\
\hline
\end{tabular}

Field Work, 2020 Significant at $P<0.05$ alpha level, $t$-cal $=-9.69, t$-crit $=1.96, d f=299$

Table 6. Summary of Dependent t-test Analysis of Influence of Co-curricular Activities on Inclination towards Dropout of Secondary School Students 
The analysis in Table 6 produced a calculated value of -9.69 when compared to the critical t-value of 1.96 at a .05 level of significance with 299 degrees of freedom, it was found that the t-value is greater than the calculated value. Based on this finding, the null hypothesis which stated that there is no significant influence of Co-curricular activities on the inclination towards dropout was not retained. This implies that there was a significant influence of co-curricular activities on the inclination towards the dropout of secondary school students.

\section{8. $\mathrm{Ho} 3$}

There is no significant influence of school rules and regulations on the inclination towards dropout of secondary school students in Akwa Ibom State?

\begin{tabular}{lllllll}
\hline Variables & n & Mean & SD & df & t.vahe $_{\text {-val }}$ & t.Cal \\
\hline School Rules and Regulation & 300 & 15.91 & 4.61 & & & \\
Dropout Tendency & 300 & 21.03 & 13.85 & & & \\
\hline
\end{tabular}

Field Work, 2020 Significant at $P<0.05$ alpha level, $t$-cal $=-7.89, t$-crit $=1.96, d f=299$

Table 7. Summary of Dependent t-test Analysis of Influence of School rules and regulations on Inclination towards Dropout of Secondary School Students

The analysis in Table 7 produced a calculated value of -7.89 when compared to the critical t-value of 1.96 at a .05 level of significance with 299 degrees of freedom, it was found that the t-value is greater than the calculated value. Based on this finding, the null hypothesis which stated that there is no significant influence of school rules and regulations on the inclination towards dropout is not retained. This implies that there was a significant influence of school rules and regulations on the inclination towards the dropout of secondary school students.

\section{$5.9 \mathrm{Ho} 4$}

There is no significant influence of teacher-student relationship on the inclination towards dropout of secondary school students in Akwa Ibom State?

\begin{tabular}{lllllll}
\hline Variables & n & Mean & SD & df & t.vahe & t.Cal \\
\hline Teacher-Student Relationship & 300 & 23.28 & 5.58 & & & \\
Dropout Tendency & 300 & 41.61 & 10.85 & & & -16.05 \\
\hline
\end{tabular}

Field Work, 2020 Significant at $P<0.05$ alpha level, $t$-cal $=-16.05, t$-crit $=1.96, d f=299$

Table 8. Summary of Dependent t-test Analysis of Influence of Teacher-Student Relationship on Inclination towards Dropout of Secondary School Students 
The result of the analysis in Table 8 above on the influence of teacherstudent relationship on students' inclination towards dropout of secondary school students showed that the calculated t-value of -16.05 when compared to the critical t-value of 1.96 at .05 level of significance with 299 degrees of freedom, the result was found the critical t-value (1.96) is greater than the calculated value $(-16.05)$. Based on this result, the null hypothesis was rejected showing that students' perception of teacher-student relationships significantly influences students' inclination to drop out of school.

\section{Discussion}

The results of the findings in this study were discussed in this section based on the research questions and hypotheses used in guiding the study.

\subsection{Test/Examinations and Students Inclination towards Dropout}

The finding on the research hypothesis revealed that inclination towards dropout by secondary school students is influenced highly by the attitude to test/examination in school. The findings revealed that students who detest test/examinations in school are more likely to drop out of school. Most students pretend to be sick during tests/examinations to be allowed by their parents to stay away from school. There is no doubt concerning this finding, students who dread tests/examinations are likely to fail and consequently dropout of school. The finding is in support of the observation of Garry (2015) who noted that many students who see themselves as incapacitated suffer greater anxiety, have little confidence and low self-esteem in their ability to withstand test/examinations, stay away from school on the date of test and examinations, and finally dropout.

\subsection{Co-curricular Activities and Students Inclination towards Dropout}

The finding revealed that co-curricular activities have highly influenced students' tendency to drop out of school. The finding suggested that students who see co-curricular activities as burdensome and time-consuming are more likely to dropout of school than those students who enjoy co-curricular activities. For instance, most students who love school games and other happenings are likely to attend school so that they can take part in those actions. The finding revealed a significant influence of co-curricular activities on the inclination towards dropout. The finding of this study corroborates the finding of Narayanan and Murphy (2017) who reported that it is the less disciplined students and students with a low ability that allow social activities like going to cinema and sporting activities to influence them and this made to drop out of school since they have little or no interest in academics. 


\subsection{School Rules and Regulations and Students Inclination towards Dropout}

The finding of research hypothesis three revealed that school rules and regulations have highly influenced students' inclination towards dropout. The findings suggested that students who see school rules and regulations as punishment or unbearable are more inclined to dropout of school than those students who see school rules and regulations as a normal thing are less inclined to dropout of school. In other words, students' tendency to dropout of the school depends greatly on how the students view school rules and regulations. Finding hypothesis three revealed a significant influence of school rules and regulations on students' inclination towards dropout. The finding is in line with the finding of Ayenibiowo and Akinbode (2011) who opined that in a school where students, especially low-achieving students perceive the rules and regulations as too strict and not supportive may choose to drop. According to the authors, students may perceive school rules and regulations as restricting them from involving in examination malpractice, smoking, using foul languages, forming confraternities, bullying, disrespecting school authorities or getting involved in delinquent behavior and so drop out from school.

\subsection{Teacher-Student Relationship and Inclination towards Dropout}

The finding of research hypothesis four revealed that the teacherstudent relationship has a high influence on the inclination towards dropout by secondary school students. The finding suggested that the way students see their teachers determine whether they would continue or dropout of school. There is no doubt that students who perceive their teachers as loving, caring, models, and so on are more likely to continue in school than those students who view their teachers as enemies, wicked and inconsiderate. Finding on hypothesis four also revealed a significant influence of perception of the teacher-student relationship on the inclination towards dropout by secondary school students. The finding is in line with the opinion of Bridge et al (2009) believe that teacher behavior towards a student is a major determinant of students' attitude towards dropping out of school. The relationship between actions and outcomes or the contingency of teachers is important to how students perform and how they stay in school.

\section{Conclusions}

Based on the findings of the study, it is concluded that a positive attitude towards co-curricular activities by students reduces dropout tendency by students and promotes school continuation. Equally, that favorable perception of school rules and regulations helps to reduced student's tendency to drop out of school. Similarly, a positive view of tests/examinations 
increases student's completion of studies. In the same vein, a positive and favorable teacher-student relationship would promote students' completion of school.

Based on the findings and conclusion of this study, the following recommendation was made: (a) Counsellors in secondary schools should organized programs for students that would help them to develop a positive attitude towards test/examinations so that they can achieve their desired academic goals; (b) Students in secondary school should not be forced to participate in any co-curricular activities that they do not wish to part take; (c) Ministry of Education should ensure that strict rules and regulations are minimized in secondary schools to reduce student's dropout tendency; and (d) Government should employ more teachers to help curb the discrepancies of teacher-student ratio to enhance a positive teacher-student relationship.

\section{References}

Anderson, C. (1982). The search for school climate. A Review of Educational Research, 52(3), 368-420. doi: 10.3102/00346543052003368

Austin, A. W. (2006). Predicting academic performance in College. New York: Free press, pp. 288-293

Ayenibiowo K.O., \& Akinbode, G. A. (2011). Psychopathology of Bullying and emotional abuse among school children. IFE Psychologia, 19(2), 127-142. doi: 10.4314/ifep.v19i2.69517

Bridgeland, J. M, Dilullo, J. J. \& Balfanz, R. (2009). On the Front Lines of Schools: Perspectives of Teachers and Principals on the High School Dropout Problem. Retriewed from http/eric.edu.gov/?id=ED509755.

Crowder, K (2003). Neighborhood Distress and School Dropout: The Variable Significance of Community Context. Social Science Research, 32(4), 659-698. doi: 10.1016/s0049-089x(03)00035-8

Donnelly L. (2015). Neighborhood Disadvantage and School Dropout: A Multilevel Analysis of Mediating Contexts [Unpublished doctoral dissertation]. The State University of New Jersey, New Brunswick, NJ, USA.

Dejung, J., \& Kenneth, D. (1986). High School Teachers and their Students' Attendance. Final Report. Eugene, OR: Center for Educational Policy and Management: College of Education, University of Oregon.

Federal Republic of Nigeria (2013). National Policy on Education. (6 $^{\text {th }}$ edition). Lagos: NERDC Press.

Garry, V. C. (2015). The Effect of Anxiety on the Course and Career Choice of High School Students [Unpublished doctoral dissertation]. Drexel Universit, Philadelphia, PA, USA. 
Gregory, A., \& Fan, X. (2011). Perceived prevalence of teaching and bullying predicts high school dropout rates. Journal of Educational Psychology, 105(1), 138-149. doi: 10.1037/a0030416

Hembree, R. (2008). Correlates causes, effects and treatment of test anxiety. Review of Educational Research, 58(1), 47-77. doi: 10.3102/003465430 58001047

Johnson, S. L. (2013). The role of bystander perceptions and school climate in influencing victims' responses to bullying: to retaliate or seek support? Journal of Criminology, 10, 41-55

Loukas, A. (2006). Examining school climate effects. Journal of Research on Adolescence, 16(3), 491-502. doi: 10.1111/j.1532-7795.2006.00504

Mildred, C. (1954). Causes of premature leaving from grammar schools. British Journal of Psychology. 24(3), 129-141. doi: 10.1111/j.20448279.1954.tb02891

Narayanan K., \& Murphy S. E. (2017). Conceptual framework on workplace deviance behaviour: A review. Journal of Human Values, 23(3), 218233. doi: $10.1177 / 0971685817713284$

Ormrod, J. E. (2019). Human learning. ( $8^{\text {th }}$ Ed.). New Jersey: Pearson

Rosenberg, M. (1960). Attitude organization and change: an analysis of consistency among attitude components. New Heaven: Yale University Press.

Udo, E. (2005). School Challenges and Students' Academic Achievement in Chemistry in Uyo Local Government Area [Unpublished doctoral PGDE Project], University of Uyo, Uyo.

William H. (1971). Personality differentials between lower division dropouts and stay-ins. Journal of College Student Personnel, 3(2), 31-39. 